Journal of Engineering and Applied Sciences 14 (Special Issue 7): 9946-9949, 2019

ISSN: 1816-949X

(C) Medwell Journals, 2019

\title{
Analysis Study of Laser Effect on Amino Acids in Cow's Milk
}

\author{
Adnan W. Al Mudhfar \\ Department of Food Scince, Faculty of Agriculture, University of Kufa, \\ PO Box. 54003, Kufa, Iraq
}

\begin{abstract}
This proposed research we suggest sterilization method depend on laser system with new three different wavelengths the laser effect on milk content from amino acid was investigated. The sterilization process by laser system used new three wavelengths 540,800 and $1100 \mathrm{~nm}$ at laser power $70 \mathrm{mw}$ and hold time 1.5 min was achieved. All the test samples was analyzed by using amino acid analyzer where all results show no significant difference with respect to control sample. All test samples with $800 \mathrm{~nm}$ show standard amino acid and essential amino acid while when we use $800 \mathrm{~nm}$ we found standard amino acid and essential amino acid, laser system at wavelength $540 \mathrm{~nm}$ produce the optimum results where the results show the good results with essential amino acid this enhancement in milk content as a result of photochemical effect in visible region.
\end{abstract}

Key words: Amino acid, milk, laser, laser wavelength, essential, region

\section{INTRODUCTION}

The amino acid is the basic unit for the formation of proteins and peptides. It is known that proteins from the basic materials that are included in the composition of many compounds with physiological functions are very important to the human body and the rest of the organisms and life is impossible without proteins (Henderson et al., 2000). In addition, the type of amino acid has an important role in the field of nutrition and determine the nutritional value of foods and the abnormal metabolism of amino acids lead to serious genetic diseases. Hence, the importance of identifying and describing the type of amino acid (Almahal, 2016).

Some living organisms such as humans and animals, need certain amino acids that cannot be synthesized within the body of the organism called the essential amino acids which must be eaten in the daily diet. Balanced diets should be all these acids with appropriate concentrations (Djabi and Djabi, 2007). Since, milk is an integrated food that is easy to digest and is used in many food industries, it has been targeted in the study of the effect of laser radiation with low capacity on the type and quantity of amino acids (Walaa, 2018).

\section{MATERIALS AND METHODS}

First: The raw milk samples were collected from known field. The milk samples were divided into four parts (Abida et al., 2004). The first raw milk without treatment and the three samples were radiated with laser wavelengths of 540, 800 and $1100 \mathrm{~nm}$, respectively at $70 \mathrm{~mW}$ laser power for time hold (exposure time) $1.5 \mathrm{~min}$ (Ward et al., 2000; Hosseini et al., 2011).

By taking $200 \mathrm{~mL}$ from raw milk and digesting it with an equal amount of $\mathrm{HCl} 6 \mathrm{~N}$ and methanesulonic acid in an oven under discharge at $110^{\circ} \mathrm{C}$ for $24 \mathrm{~h}$. Extract the emulsifier three times in equal volumes $2 \mathrm{~mL}$ of the ether to remove the reagent. Collect and evaporate the dehydration and then dissolve with $0.5 \mathrm{~mL}$ acetone and is used for chromotropic injection (Watson et al., 2006; Elmnasser et al., 2007).

Second: Preparation of the standard solution of the amino acids obtained from the chemical store in the Department of Food Sciences of the Faculty of Agriculture University of Kufa. In the liquefaction of $0.5 \mathrm{~g}$ of amino acid in $100 \mathrm{ml}$ of ethanol at a concentration of $95 \%$ and then filtered solution millipore accurate size $0.45 \mu \mathrm{m}$ promising for chromotropic injection (Murdas, 2018; Naser et al., 2018).

\section{RESULTS AND DISCUSSION}

All the collected milk samples results was compared after completing the chromatography analysis with control sample (raw milk without treatment) the results show the radiated samples with laser wavelengths (540, 800 and $1100 \mathrm{~nm}$ ) more enhancement in milk amino acid content.

Laser wavelength $540 \mathrm{~nm}$ : We can show from the Fig. 1 the amino acid ratio for milk sample treated with laser at wavelength $540 \mathrm{~nm}$ at power $70 \mathrm{~mW}$ with hold time $1.5 \mathrm{~min}$. The analysis results shows no significant variation at level 0.01 for respect ratio for treatment milk sample with control sample. The ratio and type of amino acid appear after treatment as shown below (aspartic acid, histidine, glycin, threonine, alanine, cystine, valine, methionine, tryptophane, isoleucine with ratio $(0.3,3.6$, $4.1,80,7.1,0.4,3,0.5,61.047,25.4)$. 


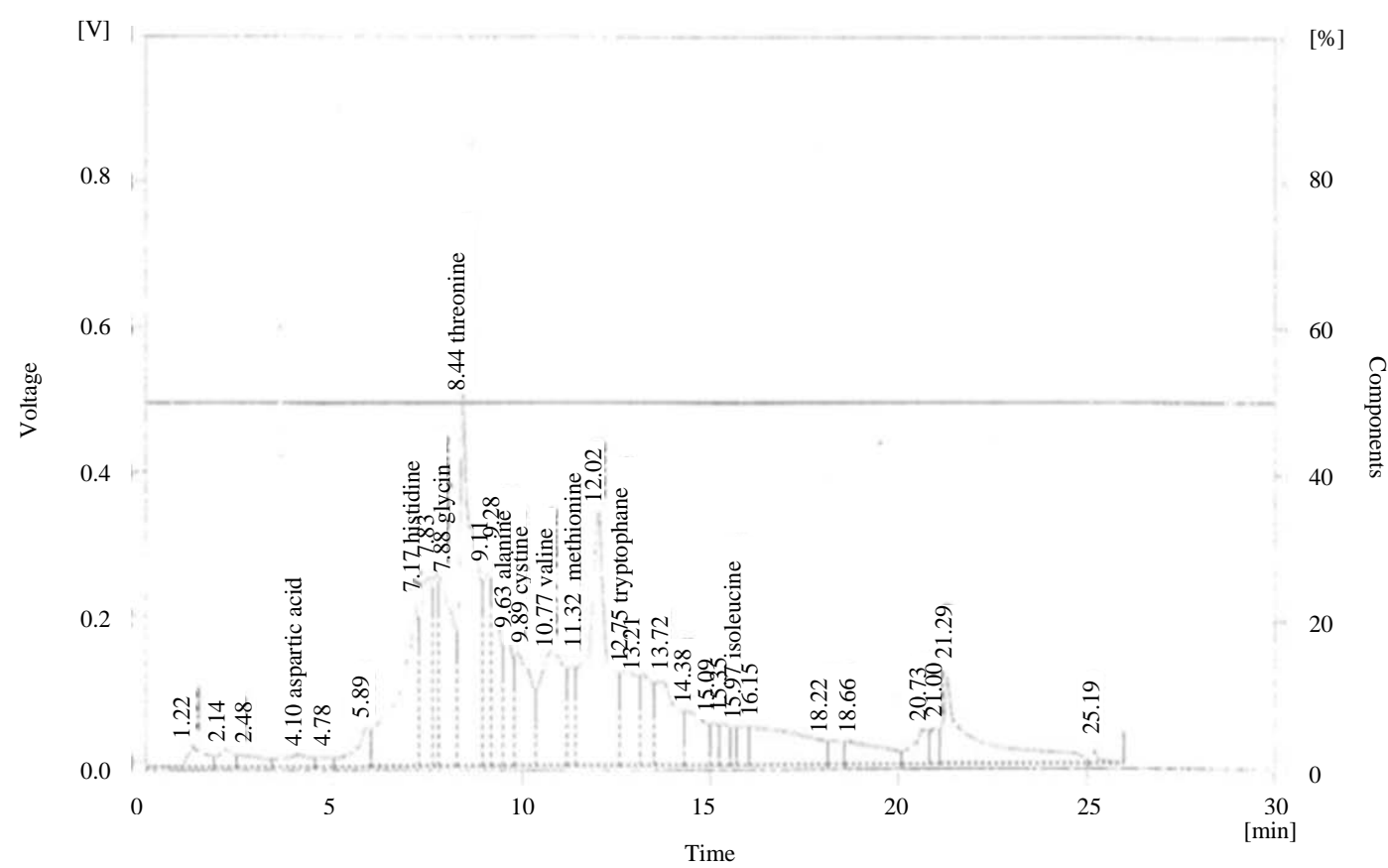

Fig. 1: The amino acid after treat with $540 \mathrm{~nm}$

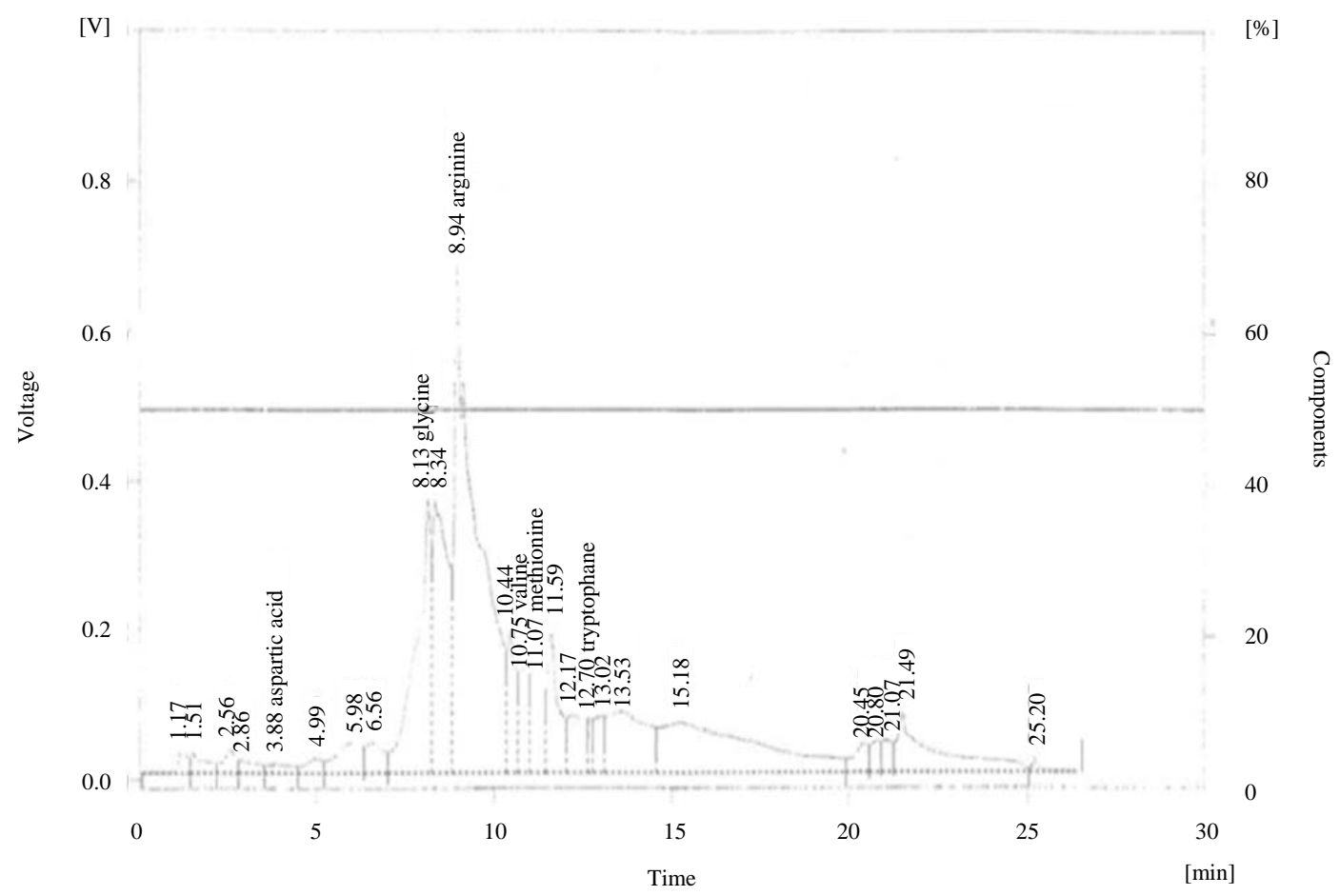

Fig. 2: The amino acid after treat with $800 \mathrm{~nm}$

This means the laser in visible region will enhance in milk content of essential amino acid where ten essential amino acid appear in treated sample if we compared with control that appear six amino acid (Fig. 2).
That the laser within the visible region stimulate the milk compound to interact with each other to produce a new amino acid called alanin through the transfer of the amino group to the other organic compounds in milk to 


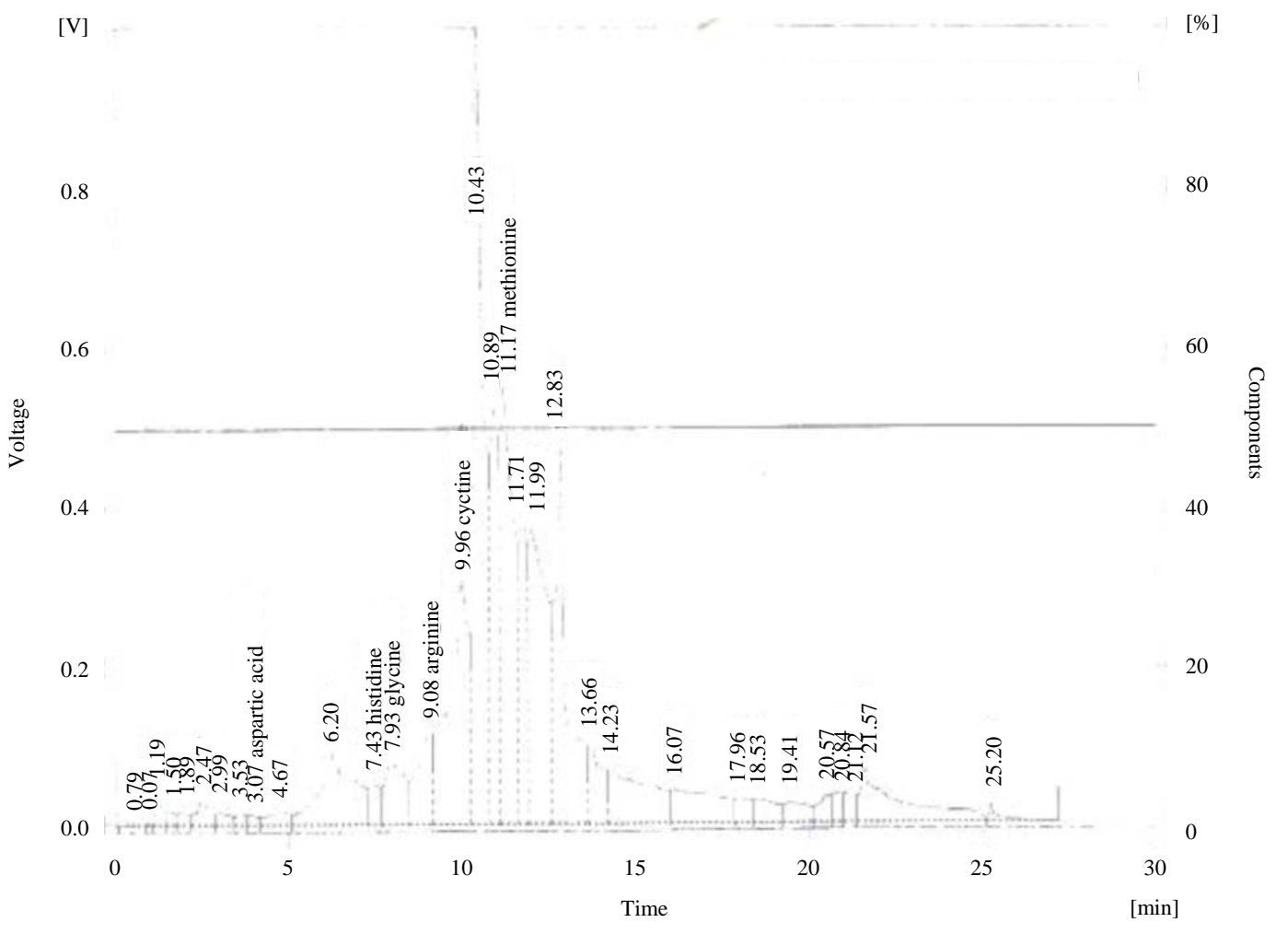

Fig. 3: The amino acid after treat with $1100 \mathrm{~nm}$

form this new amino acid which promises the source of formation spargel amino acid which is the fundamental unit to build a number of acids through special path known aspartate pathway.

Laser wavelength 800 nm: We can show from the Fig. 2 the amino acid ratio for milk sample treated with laser at wavelength $800 \mathrm{~nm}$ at power $70 \mathrm{~mW}$ with hold time $1.5 \mathrm{~min}$. The results of analysis showed no significant difference between the laser treat sample and control sample where the percentage and types of acid were as follow: aspartic acid, glycine, arginine, valine methionine, tryptophane.

At ratio 0.10.7, 25.0, 66.4, 4.5, 3.3, respectively. We can note from these results break each of serine, histidine, alanine and instead of by aspartic acid, valine, tryptophan while increasing the ratio of glycine and arginine to 25, $66.4 \%$, respectively if we compared with raw milk sample 11.8, 20.7 therefor, the sterilize by light don't miss the milk its nutritional value and also enhance sensory characteristics.

Laser wavelgth 1100 nm: We can show from Fig. 3 the amino acid ratio for milk sample treated with laser at wavelength $1100 \mathrm{~nm}$ with the same laser power and hold time. The results of analysis showed significant difference between the laser treat sample and control sample where the percentage and types of acid were as follow this difference because the laser in the infrared region absorbed strongly by milk's protein and liquid and as results convert to heat in casein particles and cause to break some amino acid: (arginine, cystine, aspartic acid, histidine, glycine, methionine) at ratio 1, 5,7, 21.7, 20.7, 10.6, 41.0\%, respectively. He has achieved each arginine, cystine, methionine increasing up to $20,10,41 \%$, respectively while in the raw milk $11,1,6,4.5 \%$. The sterilize by light of milk change from amino acid and cause to break amino acid serine at ratio 36\% and form aspartic acid and this will lead to increase the acid function of milk.

\section{CONCLUSION}

The results of proposed research shows the ability of improve the nutritional properties of bovine milk by laser sterilization system with three wavelength 540, 800 and $1100 \mathrm{~nm}$. All collected results show the equality of milk sample treated with IR laser with control sample from which the same standard amino acid but different in essential amino acid. While the milk sample treated with visible laser appear increasing in number and quality of standard and essential amino acid.

\section{ACKNOWLEDEGMENT}

The researcher would like to thank, University of Kufa for providing the research facilities. 


\section{REFERENCES}

Abida, J., B. Rayees and F.A. Masoodi, 2014. Pulsed light technology: A novel method for food preservation. Intl. Food Res. J., 21: 839-848.

Almahal, S.I., 2016. Study of the effect of Nd: YAG laser on the raw cow's milk characteristics and its sterilization. Ph.D Thesis, Sudan University of Science and Technology, Khartoum, Sudan.

Djabi, M. and S. Djabi, 2007. Study of the optical bistability in a laser containing a saturable absorber. J. Eng. Applied Sciences, 2: 1383-1386.

Elmnasser, N., S. Guillou, F. Leroi, N. Orange, A. Bakhrouf and M. Federighi, 2007. Pulsed-light system as a novel food decontamination technology: A review. Canadi. J. Microbiol., 53: 813-821.

Henderson, J.W., R.D. Ricker, B.A. Bidlingmeyer and C. Woodward, 2000. Rapid, accurate, sensitive and reproducible HPLC analysis of Amino acids. US Pat. No. 5980-1193E, Agilent Technologies, Santa Clara, California, USA. https:// www.agilent. com/cs/library/chromatograms/59801193.pdf
Hosseini, S.M., M.K. Azar-Daryany, R. Massudi and A. Elikaei, 2011. Pulsed UV laser light on Escherichia coli and Saccharomyces cerevisiae suspended in non-alcoholic beer. Iran. J. Microbial., 3: 31-35.

Murdas, I.A., 2018. Optical communication system for online detection of illicit drug in border ports. J. Eng. Applied Sci., 13: 9696-9704.

Naser, T.A., J.H. Ibrahim and L.H. Aboud, 2018. Study of the fluorescence energy transfer in laser active medium molecules (Acridine Orange and Rhodamine B) dyes. J. Eng. Applied Sci., 13: 3960-3964.

Walaa, 2018. Raw milk sterilization by using laser system manufacturing locally and study the effect of it on qualitative qualities and microbial load. MSc Thesis, Kufa University Iraq, Kufa, Iraq.

Ward, G.D., I.A. Watson, D.E.S. Stewart Tull, A.C. Wardlaw, R.K. Wang, M.A. Nutley and A. Cooper, 2000. Bactericidal action of high power Nd: YAG laser light on Escherichia coli in saline suspension. J. Applied Microbial., 89: 517-525.

Watson, I., C.B.A. Yeo and D. Stewart Tull, 2006. Scanning $\mathrm{CO}_{2}$ laser bacterial inactivation systems. J. Applied Microbial., 102: 766-773. 